\title{
Environmental Responsiveness in Australia's Bus and Coach Supply Chain
}

\author{
Ann M. Brewer \\ Institute of Transport Studies, The University of Sydney
}

\begin{abstract}
$\overline{\text { Abstract }}$
The responsiveness of business enterprises to the natural environment is of great concern to both the government and industrial sectors in Australia. A key question emerges as to which industries are environmentally more responsive than others. This article examines transportation's contribution to greenhouse gas (GHG) emissions. It identifies and describes environmental responsiveness within Australia's bus and coach sector, a major operator of passenger transport. This sector is defined in the full context of the supply chain; that is, the integration of business processes from manufacturers and suppliers of vehicles and fuel to the providers of services and information for the benefit and value of customers.

The article focuses on the perceptions that bus and coach operators have about environmental opportunities and associated risks. Twenty-six key stakeholders were invited to participate in either a survey or case study designed to ascertain energy and waste management practices. Environmental responsiveness occurs when it has the greatest potential impact on the "bottom line" of both the environment and the business. While operators initiated waste and energy management programs to be socially responsible, the continuation of these practices depended on their cost effectiveness to the business. A number of specific actions are warranted based on the study's findings.
\end{abstract}




\section{Introduction}

In the 1990s, there has been an increase in worldwide public awareness of environmental issues and the necessity for their management (Bhate and Lawler 1997). A strategic concern of both government and industry in Australia has been the extent of responsiveness of businesses across all industries to the natural environment. Protecting the environment essentially involves reconciling ecological issues and values with economic interests and business responsibilities.

The rise in GHG emissions is due primarily to the burning of fossil fuels and deforestation. GHG contributes to global warming, which, in turn, increases the potential incidence of catastrophes such as potent and frequent windstorms, rainfall, floods, mud slides, hailstorms, drought, crop damage, and wildfire (Mills 1998). Each of these catastrophes presents massive costs to society. Industrial activities are also having a detrimental impact on the environment, as demonstrated by the increase in the atmospheric concentrations of GHG, accumulation of wastes, and pollution of ground and surface water. Many of these environmental changes are happening swiftly, and some are irrevocable.

What was thought to be critical management of the natural environment in the 1970s may not be the case today. More so than ever before, the environment has to become a significant factor in shaping business practice as management develops policies, programs, and tools to address environmental pressures. A key question emerges as to which industries are environmentally more responsive than others. This article examines transportation's contribution to GHG emissions, specifically the responsiveness among bus and coach operators. The article addresses five themes that represent the central tenets of environmental commitment in the bus and coach industry:

1. Key influences on vehicle purchases

2. Types of operations perceived as factors in GHG emissions production

3. Nature of energy and waste management programs

4. Environmental auditing

5. Industry outlook in the supply chain 


\section{Australia's Bus and Coach Industry}

Australia's bus and coach sector integrates business processes from manufacturers and suppliers of vehicles and fuel to the providers of services and information. Table 1 lists the key players in the supply chain of the bus and coach transport sector as well as their energy and waste generation characteristics.

The potential impact on energy and waste efficiency by bus and coach operators should not be overlooked. From 1994 to 1995 , the transport sector contributed 12 percent of all GHG emissions, of which the bus sector accounted for only 0.9 percent (Apelbaum Consulting Group 1997). During the same period, bus and coach operators consumed 4.7 percent (398 megaliters) of the total fuel

\begin{tabular}{|c|c|c|c|c|c|c|}
\hline \multicolumn{7}{|c|}{$\begin{array}{c}\text { Table } 1 \\
\text { SCM by Energy/Waste Generation Characteristics }\end{array}$} \\
\hline $\begin{array}{l}\text { Energy/Waste Generation } \\
\text { Characteristics }\end{array}$ & $\begin{array}{l}\text { Chassis } \\
\text { Suppliers }\end{array}$ & $\begin{array}{l}\text { Body- } \\
\text { builders }\end{array}$ & $\begin{array}{l}\text { Vehicle } \\
\text { Component } \\
\text { Suppliers }\end{array}$ & $\begin{array}{l}\text { Fuel } \\
\text { Suppliers }\end{array}$ & $\begin{array}{l}\text { Bus and } \\
\text { Coach } \\
\text { Operators }\end{array}$ & $\begin{array}{c}\text { Commercial } \\
\text { Waste } \\
\text { Companies }\end{array}$ \\
\hline $\begin{array}{l}\text { Manufacture of components- } \\
\text { production system }\end{array}$ & $\sqrt{ }$ & & $\sqrt{ }$ & & & \\
\hline \multicolumn{7}{|l|}{ Materials selection } \\
\hline Testing of components' quality & & & $\sqrt{ }$ & $\sqrt{ }$ & & \\
\hline Production of chassis & $\sqrt{ }$ & & & & & \\
\hline Fuel cracking & & & & $\sqrt{ }$ & & \\
\hline Fuel refining & & & & $\sqrt{ }$ & & \\
\hline Fuel testing & & & & $\sqrt{ }$ & $\sqrt{ }$ & \\
\hline Fuel storage and maintenance & $\sqrt{ }$ & $\sqrt{ }$ & & $\sqrt{ }$ & $\sqrt{ }$ & \\
\hline Depot/plant design & $\sqrt{ }$ & $\sqrt{ }$ & $\sqrt{ }$ & $\sqrt{ }$ & $\sqrt{ }$ & \\
\hline Materials used in depot/plant & $\sqrt{ }$ & $\sqrt{ }$ & $\sqrt{ }$ & $\sqrt{ }$ & $\sqrt{ }$ & \\
\hline Painting & $\sqrt{ }$ & $\sqrt{ }$ & $\sqrt{ }$ & & $\sqrt{ }$ & \\
\hline Vehicle maintenance & & & & & $\sqrt{ }$ & \\
\hline Depot maintenance & & & & & $\sqrt{ }$ & \\
\hline Waste disposal methods-fuels & $\sqrt{ }$ & $\sqrt{ }$ & $\sqrt{ }$ & $\sqrt{ }$ & $\sqrt{ }$ & $\sqrt{ }$ \\
\hline Waste disposal methods-solids & $\sqrt{ }$ & $\sqrt{ }$ & $\sqrt{ }$ & $\sqrt{ }$ & $\sqrt{ }$ & $\sqrt{ }$ \\
\hline $\begin{array}{l}\text { Waste disposal methods- } \\
\text { other liquids }\end{array}$ & $\sqrt{ }$ & $\sqrt{ }$ & $\sqrt{ }$ & $\sqrt{ }$ & $\sqrt{ }$ & $\sqrt{ }$ \\
\hline
\end{tabular}

Hensher, D. A., A. M. Brewer, J. King, and M. Coulson. 1998. Scoping study, greenhouse gas emissionsbus and coach sector. Report prepared for the Greenhouse Challenge Office. Institute of Transport Studies, the University of Sydney, p. 15.

Vol. 2, No. 3, 1999 
used by the transport industry. In the year 1995 to 1996, buses (public and private) represented 38 percent of the urban public transport task in terms of passenger kilometers and 54 percent of urban public transport task in terms of number of passengers (BTCE 1996). The bus and coach sector delivers long-distance services to 15 percent of the total private and public transport users and tour/hotel shuttle services to 47 percent of the total international visitors to Australia (Bureau of Tourism Research 1996). In 1998, fleet size was estimated at 15,578, and the number of private operators at about 2,456 (ABCA 1998).

Supply Chain Management (SCM) is the effective control of all business processes occurring within and among enterprises. The ability of bus and coach operators to manage the full extent of the supply chain is contingent on the consequence of each component activity to their business as well as their managerial capability to do so. The principal processes of SCM for bus and coach operators include:

- acquiring vehicles, fuel, and labor,

- making efficient use of inputs (finance, people, technology, time, information) relative to outputs,

- producing outputs of services,

- conducting maintenance and administrative processes effectively,

- investing in appropriate technologies and services,

- conforming to regulations and rules governing the industry in which they operate, and

- $\quad$ satisfying the interests of primary stakeholders.

Careful review of these activities suggests that, in order for bus and coach operators to achieve organizational effectiveness, a balanced distribution of resources across each of these processes is needed. A business remains effective as long as it strives continuously to use its resources in an efficient manner and contributes to the wider system, which requires recognizing environmental opportunities and risks. Environmental responsiveness arises from the processes and arrangements that management use to take action (mostly requiring 
extraordinary effort and investment) to deal with various environmental pressures that confront operators in conducting their business (Brewer 1994).

Moreover, environmental responsiveness leads to appropriate actions mostly in situations where it costs the operator little. From the operator's perspective, isolated managerial action will be less effective because improvement in environmental quality requires concerted industry action. While environmental responsiveness can be measured by operators' activities, it is essentially a philosophical stance that industry holds in relation to the environment that influences managerial practices, which in turn, impact philosophy.

In general, management needs to optimize two, often conflicting, objectives: organizational effectiveness and the minimization of environmental risks. Little is known about how bus and coach operators perceive their natural environment and respond to changes (including regulatory) within it. This article focuses on three issues:

1. Are bus and coach operators taking the necessary steps toward managing the environment?

2. In this regard, what influences their decisions?

3. In order to promote effective environmental responsiveness, an essential first step is to appreciate the factors perceived by operators to be important enough for them to engage in strategies that sustain the natural environment.

\section{The Study}

A project investigating the perceptions of bus and coach operators in understanding environmental opportunities and risks was undertaken. Twentysix key stakeholders (chassis manufacturers, bodybuilders, oil companies, government/regulators, bus and coach operators, and industry associations) representing the main subsectors of the industry were also invited to participate in either a survey or case study designed to elicit information about perception and strategies for managing energy and waste. A fax out/fax back self-administered survey was designed.' The response rate was 69 percent.

In addition, interviews were held with management and workshop supervisors of one private and one public operator in Sydney. An on-site tour of 
depots and workshops of each operator was conducted to review both energy and waste management procedures in operation. Figure 1 presents a profile of the survey respondents from the bus and coach sector.

\section{Findings}

This section summarizes key issues identified that may facilitate or impede the environmental responsiveness of bus and coach operators. Each theme represents a major business decision by operators in running their enterprises.

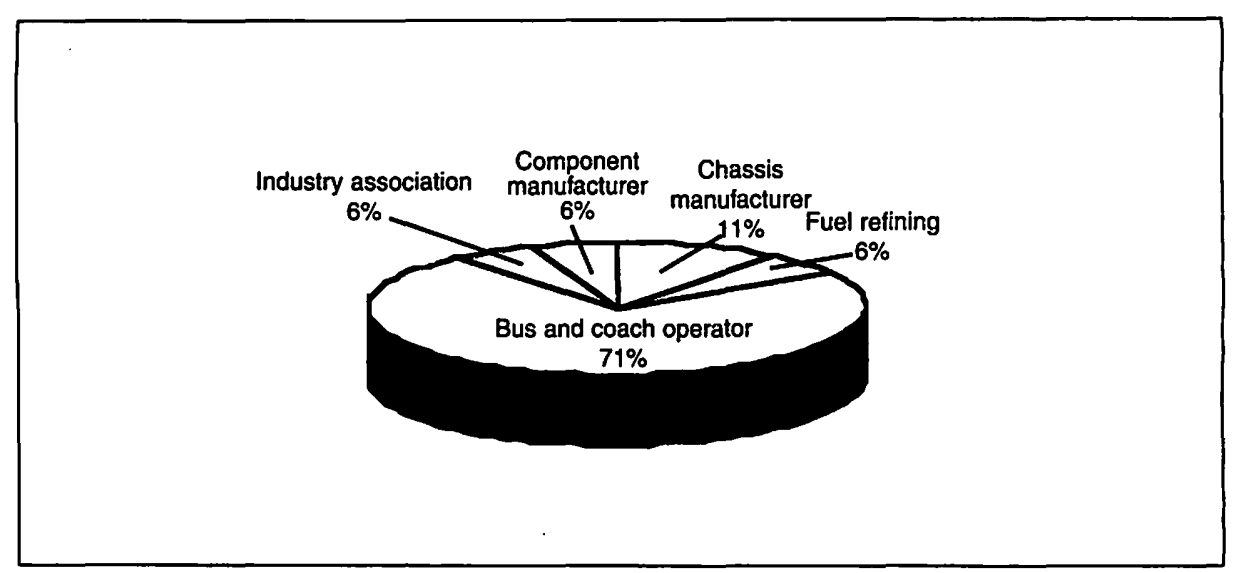

Figure 1. Profile of survey respondents

\section{Key Influences on Vehicle Purchases}

The key influences in vehicle purchase decisions made by operators are shown in Figure 2. The decision to purchase one vehicle or augment an existing fleet is a complex interaction of factors. The most important factors in the vehicle purchase decision are vehicle reliability, purchase price, vehicle specifications, and fuel consumption. These factors are rated ahead of vehicle resale value. The decision-making process varies for operators depending on whether they are government, private, family-owned, large or small enterprises, and physical location of the depot.

In terms of policy, operators are consumers, and this fact provides governments with an opportunity to intervene in the marketing of products by suppliers. The question arises as to the nature of government intervention. 


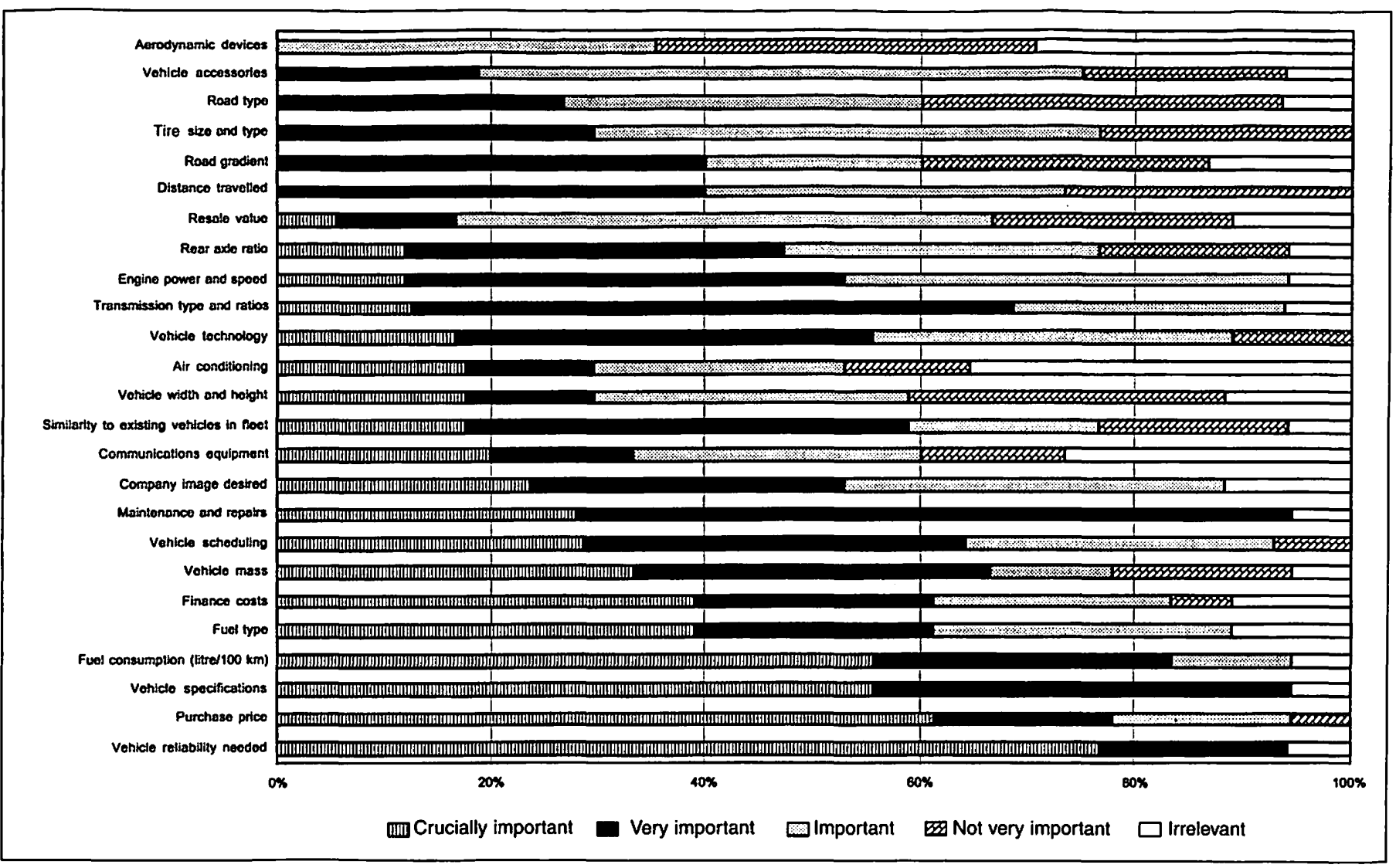

Figure 2. Survey results summary: Key influences on vehicle purchases (ranked) 
Information is one way to disseminate data to operators about the environmental advantages and disadvantages of different types of purchasing outcomes. For example, when purchasing a vehicle, bus and coach operators trusted that they were provided with highly reliable information on total vehicle fuel economy and associated environmental benefits. This was not always the case. In addition to being able to rely on manufacturers' and suppliers' information, operators wanted opportunities to discuss issues, such as vehicle and fuel efficiency, with experts and key industry players. The decision to purchase a vehicle has long-term impacts as it influences fleet type and maintenance contracts. This is a major operational constraint for operators.

\section{Types of Operations Perceived as Factors in GHG Emissions Production}

The most important factors in emissions production are vehicle technology, fuel type, fuel consumption, maintenance and repairs, vehicle reliability, and similarity to existing vehicles in the fleet (Figure 3). Interestingly, these factors contrast with those perceived as important in vehicle purchasing (Figure 2). The distinction lies mainly in the perceived importance of purchase price associated with vehicle purchases by operators. Purchase price acts as a proxy and may be confounded by other factors in the decision-making process. Also noteworthy is the fact that engine power and speed and distance traveled ranked lower in terms of the importance of perceived factors in emissions production. The case studies showed that driver training was also an important factor in reinforcing the way driving patterns influence emissions production.

Emission controls, according to Taylor (1988), are the most efficient means to prevent global warming. On this basis, operators rated a list of sources of GHG emissions according to what they believed are the greatest and least potential gains in managing them (Figure 4). The most important factors in managing emissions production include exhaust emissions, storm water, leakage of fuel storage systems, used paper, brake fluid, paint waste, solvents/thinners, and used batteries. Engine parts was seen as the least important factor in emissions production. Overall, operators were undecided as to the greatest and least potential gain from the management of sources of GHG emissions. This finding suggests a greater need for information not only about sources of GHG emissions but also their management in the workplace. 


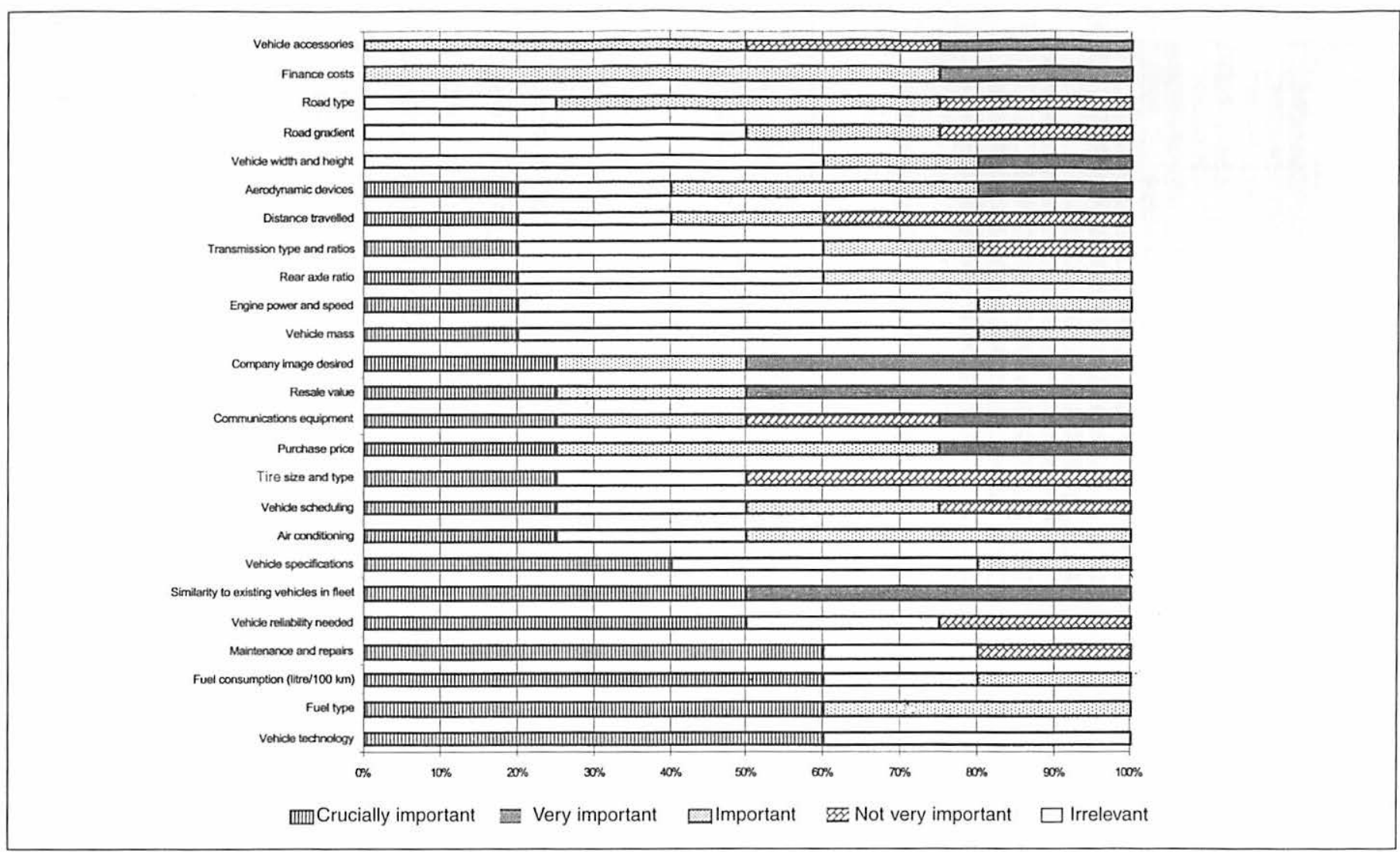

Figure 3. Survey results summary:

Importance of various factors in emissions production (ranked) 


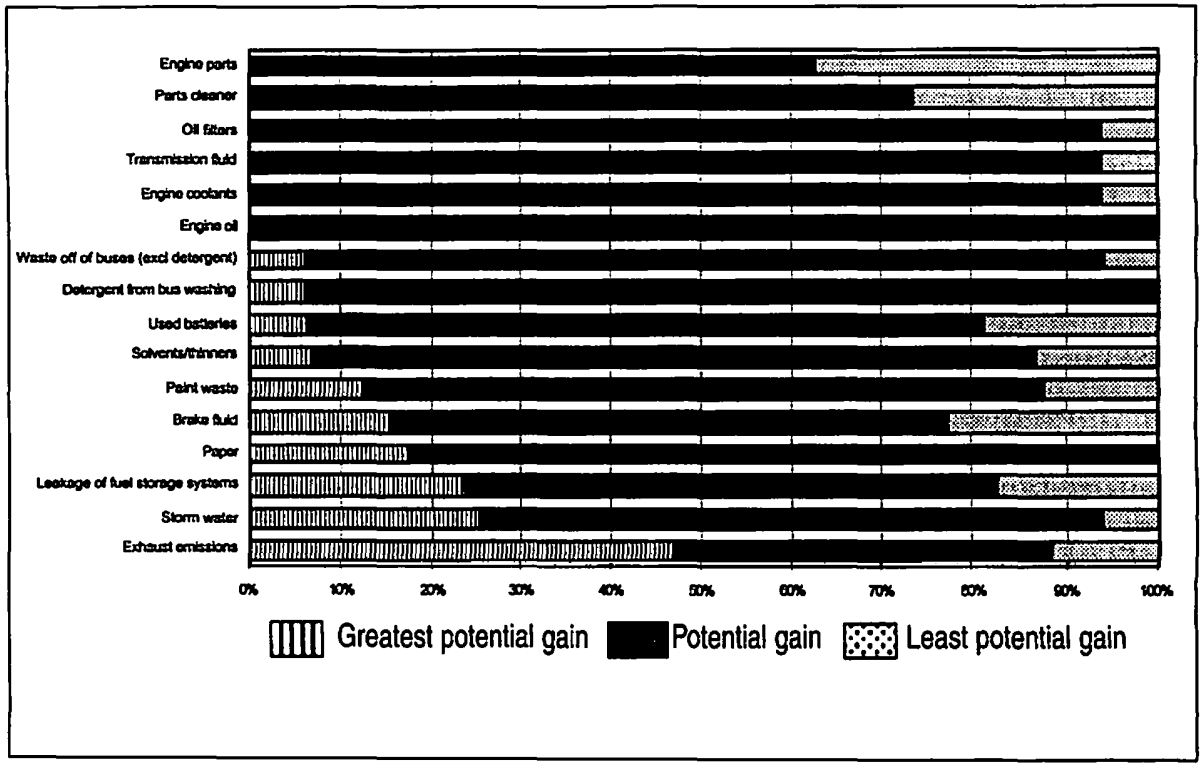

Figure 4. Survey results summary: Sources of GHG emissions (ranked)

\section{Nature of Energy and Waste Management Programs}

Bus and coach operators were asked to list six operational processes that they believed contributed to either the generation or release of GHG emissions. Identifying these activities was not straightforward for most operators. The most frequently listed activities included operating buses, painting (spray, etc.), use of diesel fuel engines, washing and cleaning of buses, and electricity usage.

The two case studies confirmed that it is difficult for public and private operators to get high-quality information about sources of GHG emissions. Notwithstanding operational constraints, not the least of which is cost, operators report that they are trying to reduce energy use and improve waste management. However, little information is available from either government or industry about the types of activities, products, or by-products that contribute directly or indirectly to GHGs or any other negative environmental outcome within the bus and coach sector. 
Bus and coach operators were asked to identify three energy/emission programs that they believed contributed to industry best practices. The most frequently named energy management programs in use were: compressed natural gas (CNG) bus trials/use of CNG engines, fuel improvement programs, recycling of bus washing water, treatment of waste, use of better/higher specified engines (e.g., Euro II diesel engine), reduced electricity usage, and energy management.

Operators examine their energy bills carefully, making comparisons with previous billing periods, and generally look for information on how to conserve energy in their business. To cut back on the use of electricity, for example, some operators have put skylights in the depots, installed improved lighting technology, and added timers to switches. The use of tinted windows has reduced air-conditioning in buses and coaches and also has resulted in the use of more effective "refrigerants" in equipment.

Despite these measures, there is generally not a good understanding of what is energy intensive in the workplace, particularly in back-office areas. The problem is that most information and search tools that operators rely on are insufficient for the purpose. Operators believe it is difficult to acquire information about the type and nature of energy management programs in use in the industry. It is up to individual operators to network with each other and gain access to each other's depots-not an easy process in a competitive situation.

While operators accept products upstream on the supply chain, they pass waste and costs downstream. For example, oil sludge, old oil, dry waste, shredded paper, paint and thinners, and worn-out batteries and tires are collected by commercial operators who dispose of or recycle them. Operators identified the major waste activities using fossil fuel-derived energy as electricity usage and operation of vehicles, computers, offices, and depots. Most operators attempt to recycle oil, water, and tires to minimize costs and landfill deposits. Some have installed their own irrigation for washing vehicles to allow wash water and run off to be recycled for further use. Others have engaged in procedures that maximize the use of recycled materials such as paper and toner cartridges for printers. 
Waste management, including prevention, is widely appreciated by bus and coach operators, but is seen essentially as an added cost, incurred through inspection, maintenance, rework, and liability risk. Recycling does not guarantee a direct payoff for operators since waste collection and its dispatch is a costly exercise. Consequently, a key issue for environmental management is what commercial operators do with waste.

\section{Environmental Auditing}

Information about environmental auditing assists in understanding the impediments to energy and waste management as well as the quality of the auditing process. Bus and coach operators were asked to identify examples of environmental auditing that specifically focused on reducing GHG emissions in each phase of the supply chain. Some examples of environmental auditing are listed in Table 2. Overall, maintenance was the main approach to auditing, which meant that isolated aspects of operations were frequently monitored. This approach is piecemeal. An auditing process should reflect a more integrated and total quality approach.

In contrast to chassis manufacturers, fuel refining plants, and the public operator, the auditing process among private operators is largely ad hoc. Table 2 depicts the level of awareness of bus and coach operators in terms of environmental auditing processes that explicitly look at ways to reduce GHG emissions. However, there is no indication that these auditing processes are administered as part of bus and coach operations. On the whole, operators do not maintain audit databases so there is little opportunity at present to survey audit systems for important sources of information about energy and waste management programs. If energy and waste management are to have a significant impact on GHG emissions, their impact should be traceable through audit data, transforming audit databases into tools for evaluating environmental responsiveness. Auditing has the additional advantage of providing useful information to operators about outcomes of the energy strategies implemented.

Implementing more efficient forms of environmental auditing is a major challenge facing most enterprises. However, having an efficient management information system does not necessarily translate into good environmental prac- 


\section{Table 2}

Survey Results Summary: Examples of Environmental Auditing in Bus and Coach Operations

\begin{tabular}{lcc}
\hline Item (listed in order of highest number of incidence) & Frequency: Count & Percent \\
\hline Regular preventive maintenance & 4 & 20 \\
Monitor fuel consumption via transponder & 2 & 10 \\
Check periodically that operation complies to relevant laws & 1 & 5 \\
Audit fuel usage & 1 & 5 \\
Audit electricity usage & 1 & 5 \\
Use better gearbox and engine technology & 1 & 5 \\
Routine servicing to reduce oil and fuel leakage & 1 & 5 \\
Bus lanes and priority measures & 1 & 5 \\
Bus idling at terminals & 1 & 5 \\
Vehicle testing of emissions & 1 & 5 \\
Better fuel usage & 1 & 5 \\
Six weekly visual emissions checks on all & 1 & 5 \\
Route planning & 1 & 5 \\
Driver training & 1 & 5 \\
Maintenance of equipment and consumables & 1 & 5 \\
Reduce exhaust emissions & 1 & 5 \\
Total & 20 & $\mathbf{1 0 0}$
\end{tabular}

tices. This can be attributed to ad hoc decision-making by management and lack of resources to evaluate compiled data, as well as the lack of implementation of good environmental practices either through ignorance, lack of expediency, or because energy and waste are not viewed as strategic business processes.

\section{Industry Outlook in the Supply Chain}

Table 3 shows the extent to which stakeholders (i.e., all members in the supply chain) can be considered environmentally responsive. It presents the most frequent statements that gained agreement and disagreement. At the top of the list, most respondents believe that as vehicles age they will be replaced by more fuel-efficient vehicles. There is strong agreement with the need to improve the quality of diesel/distillate in order to reduce GHGs. However, respondents do not believe that the conversion to CNG saves up to 50 percent 
in operating costs, as claimed in the technical literature (Erdos 1998). They do believe that the bus and coach sector is bereft of information about energy and emission management programs. The industry is optimistic that Euro II, the emission standard in Europe, is achievable by 2002. The introduction of bus infrastructure, such as bus priority systems and more flexible time-tabling coupled with minibuses, will also impact the reduction of GHG emissions.

While not opposed to the use of CNG vehicles, there is some concern about the introduction of these vehicles into the private bus sector. Stakeholder disagreement centers around fuel efficiency and a perception that diesel/distillate contributes to GHG emissions. Respondents are not optimistic about the penetration of alternative fuels. A report by Dickson-Simpson (1998) suggests that studies by London Buses demonstrated that a diesel bus with a catalytic exhaust is the only cost-effective way to become environmentally friendly. The report stated, "The ECS catalyzer works on today's ordinary diesel fuel with up to 0.05 percent ( 500 parts per million [PPM]) sulfur. London Transport uses it in conjunction with ultra-low sulfur fuel (less than 50 PPM). The reason is that this light fuel has been effective in particulates reduction-cutting them by 32 percent. Adding the ECS catalyzer as well cuts particulates by up to 54 percent."

In addition, $\mathrm{CNG}$ poses a space problem for passengers, thereby impacting the number of $\mathrm{CNG}$ vehicles required to replace one diesel vehicle equivalent. This issue needs to be analyzed in the context of real-life operations in order to assess patronage levels, vehicle replacement trends, and vehicle deployment.

Commitment to the environment might be judged by the fact that the majority of respondents (94\%) believe that energy and waste management is an important part of the business strategy for the industry. For example, waste management is a legislated component of the occupational health and safety program for operators in Australia. About 50 percent of management conduct regular (i.e., weekly or monthly) depot audits (unofficial) to ensure efficient energy and waste practices. For example, they may perform regular checks on fuel efficiency in order to identify leaks. Reviewing energy costs is also a high priority. While 
Table 3

Survey Results Summary: Stakeholder Views

\begin{tabular}{|c|c|c|c|}
\hline $\begin{array}{c}\text { Strong Agreement } \\
\text { (Percentage of "totally agree" responses) }\end{array}$ & Rank & $\begin{array}{c}\text { Strong Disagreement } \\
\text { (Percentage of "disagree" responses) }\end{array}$ & Rank \\
\hline $\begin{array}{l}\text { As vehicles are replaced, the replacement } \\
\text { is much more fuel efficient than the } \\
\text { disposed vehicle }\end{array}$ & $\begin{array}{c}1 \\
77 \%\end{array}$ & $\begin{array}{l}\text { Private bus companies are not taking } \\
\text { up the opportunity to use CNG buses } \\
\text { simply because the success of the } \\
\text { technology in penetrating that } \\
\text { market is very slow }\end{array}$ & $\underset{66 \%}{1}$ \\
\hline $\begin{array}{l}\text { Staff in the industry generally have little } \\
\text { idea of what an energy/emissions } \\
\text { management program is }\end{array}$ & $\begin{array}{c}1 \\
77 \%\end{array}$ & $\begin{array}{l}\text { The conversion to CNG saves up } \\
\text { to } 50 \% \text { in operating costs }\end{array}$ & $\begin{array}{c}2 \\
56 \%\end{array}$ \\
\hline $\begin{array}{l}\text { Establishing ways of improving the quality } \\
\text { of diesel/distillate content to reduce sulfur } \\
\text { content and GHG emissions is a priority issue }\end{array}$ & $\begin{array}{c}2 \\
65 \%\end{array}$ & $\begin{array}{l}\text { Private bus and coach operators are } \\
\text { generally opposed to alternatively } \\
\text { fueled vehicles (e.g., CNG) }\end{array}$ & $\begin{array}{c}3 \\
50 \%\end{array}$ \\
\hline $\begin{array}{l}\text { Better infrastructure for bus movements } \\
\text { will reduce GHG emissions from bus } \\
\text { operators }\end{array}$ & $\begin{array}{c}3 \\
61 \%\end{array}$ & $\begin{array}{l}\text { Having CNG tanks in a bus and coach } \\
\text { depot takes up too much space }\end{array}$ & $\begin{array}{c}4 \\
44 \%\end{array}$ \\
\hline $\begin{array}{l}\text { Staff in the industry generally have little } \\
\text { idea of what a waste management program is }\end{array}$ & $\begin{array}{c}4 \\
56 \%\end{array}$ & $\begin{array}{l}\text { An impediment to the take-up of } \\
\text { alternative fuels is the small market } \\
\text { for new buses and coaches in Australia }\end{array}$ & $\begin{array}{c}5 \\
39 \%\end{array}$ \\
\hline $\begin{array}{l}\text { An impediment to the take-up of alternative } \\
\text { fuels is the small market for new buses and } \\
\text { coaches in Australia }\end{array}$ & $\begin{array}{c}4 \\
56 \%\end{array}$ & $\begin{array}{l}\text { Using smaller vehicles such as } \\
\text { minibuses will enable operators to } \\
\text { provide more flexible time-tabling } \\
\text { of services }\end{array}$ & $\begin{array}{c}5 \\
39 \%\end{array}$ \\
\hline $\begin{array}{l}\text { To have Euro II or U.S. } 98 \text { standards by } \\
2002 \text { is achievable }\end{array}$ & $\begin{array}{c}4 \\
56 \%\end{array}$ & $\begin{array}{l}\text { The diesel/distillate supplied to the bus } \\
\text { and coach operators is the major } \\
\text { culprit in producing GHG emissions } \\
\text { in end-use operations }\end{array}$ & $\begin{array}{c}6 \\
35 \%\end{array}$ \\
\hline $\begin{array}{l}\text { If government introduced more stringent } \\
\text { regulations and fines on levels of sulfur in } \\
\text { diesel, then the oil companies may finally } \\
\text { sort out this major pollutant problem }\end{array}$ & 5 & $\begin{array}{l}\text { Most bus and coach operators are not } \\
\text { prepared to invest in CNG vehicles } \\
\text { until fuel prices are as attractive } \\
\text { as conventional fuel prices }\end{array}$ & $\begin{array}{c}6 \\
35 \%\end{array}$ \\
\hline $\begin{array}{l}\text { Bus and coach operators are committed to } \\
\text { reducing GHG emissions }\end{array}$ & $\begin{array}{c}6 \\
50 \%\end{array}$ & $\begin{array}{l}\text { My industry sector does take } \\
\text { environmental protection seriously } \\
\text { enough }\end{array}$ & $\begin{array}{c}7 \\
33 \%\end{array}$ \\
\hline $\begin{array}{l}\text { Most bus and coach operators are not } \\
\text { prepared to invest in CNG vehicles until } \\
\text { fuel prices are as attractive as conventional } \\
\text { fuel prices }\end{array}$ & $\begin{array}{c}7 \\
41 \%\end{array}$ & $\begin{array}{l}\text { The regulatory environment under } \\
\text { which we operate imposes a major } \\
\text { constraint on our industry's ability } \\
\text { to reduce GHG emissions }\end{array}$ & $\begin{array}{c}7 \\
33 \%\end{array}$ \\
\hline
\end{tabular}

Vol. 2, No. 3, 1999 
commitment to the environment is reflected in the survey findings, these perceptions are not mirrored in operators' official communications (once or twice a year) to or the training of staff (less than a third). In time, this will be reflected in how customers view the quality of service as it is modified to meet effective environmental business policy. Service indicators that are potentially modified by environmental responsiveness include vehicle specification and reliability, response time, staff competence, and communications with customers.

In summary, there is a high level of industry support for enhanced management of energy and waste. However, it is one thing to observe how to improve energy and waste efficiency and it is another to implement mitigating actions to address environmental issues. Drawing on the study's findings, the most appropriate means for achieving this is through integrating energy and waste management (e.g., the auditing process, benchmarking, driver training, and education programs for operators) with the business strategy.

Table 4 summarizes suggestions for regulatory changes that will assist operators in becoming more environmentally responsive. The highest priority is education, followed by implementing bus priority measures (by road authorities), minimizing vehicle mass limits. Education is also a priority due to the lack of knowledge about alternative energy sources and environmental best practices. The imposition of government regulations does not guarantee that operators will comply with or understand these rules. Justification for other regulatory changes such as increased incentives or taxes on car use must be based on social benefits not already reflected in other pricing structures. Alternatively, it may be preferable to choose some other means of having environmental factors influence operator choices about energy and waste management.

\section{Conclusions}

Environmental responsiveness occurs when it has the greatest potential impact on the bottom line of both the environment and the business. Operators will initiate waste and energy management programs so as to be socially responsible and continue with them providing they are cost effective. A number of specific actions are warranted based on the study's findings, including: 
Table 4

Survey Results Summary: Regulatory Changes Assisting the Industry

\begin{tabular}{lcc}
\hline Item (listed in order of highest number of incidence) & Frequency: Count & Percent \\
\hline Education (more information on how to achieve more responsible & & \\
environmental practices) & 2 & 6.7 \\
Introduce more bus priority measures & 2 & 6.7 \\
Vehicle mass limits (greater mass limits for buses and coaches) & 2 & 6.7 \\
Testing of vehicles for pollution & 1 & 3.3 \\
Give incentives to pollute less & 1 & 3.3 \\
Taxing car usage in urban areas & 1 & 3.3 \\
Legislate excise on CNG-“NIL EXCISE" & 1 & 3.3 \\
Remove all excises from fuel for bus fleets & 1 & 3.3 \\
Introduce Euro Il & 1 & 3.3 \\
Financial incentives for use of CNG & 1 & 3.3 \\
Better control of emissions on motor vehicles & 1 & 3.3 \\
Diesel fuel standard CEC (500 PPM) maximum & 1 & 3.3 \\
Reduced tax on low-sulfur fuel & 1 & 3.3 \\
Focus should be on Euro standards (EPA current reliance on & & 3.3 \\
California standards) & 1 & 3.3 \\
Government to take holistic approach to oil industry & 1 & 3.3 \\
Price deregulation and removal of sites act to allow competition & 1 & 3.3 \\
Give assistance to operators with older buses modified to meet Euro standards & 1 & 3.3 \\
Low-sulfur fuel & 1 & 3.3 \\
Maintain no excise on natural gas & 1 & 3.3 \\
Tax relief for CNG use & 1 & 3.3 \\
Better planning of road networks & 1 & 3.3 \\
Tax incentives to increase patronage & 1 & 3.3 \\
Funding needed to change capital to benefit environment & 1 & 3.3 \\
Review fuel suppliers' quality of fuel & 1 & 3.3 \\
Financial assistance based on emissions & 1 & 3.3 \\
Remove all speed humps on bus routes & 1 & 3.3 \\
Minimize car or truck use in poorly planned areas & 30 & \\
Total & & \\
\hline
\end{tabular}

- educating operators to enable them to integrate environmental responsiveness within their business strategy,

- switching from polluting and resource-degrading vehicles and fuels to efficient, environmentally effective vehicles and fuels,

- providing better information systems and auditing of operational processes in relation to energy conservation and waste management, and

- involving and training employees to ensure that individual businesses can extract pertinent and specific information about everyone's perception regarding the enterprise's responsibility to the environment. 
Stakeholders in the bus and coach supply chain acknowledge the significance of adopting a positive attitude toward conserving the environment, albeit that their industry contributes a relatively small percentage to GHG emissions. The switch to improved fuel and vehicle technologies and information management industrywide will lessen the impact of the bus and coach industry on the natural environment. More efficient practices and better use of information could potentially reduce environmental degradation. The main perceived obstacle in stakeholders becoming more environmentally responsive is a general lack of information and data about the efficiency of vehicles and fuel (and to minimize conflicting evidence about this). More importantly, operators must be made aware of the direct benefits of environmental management to the profit of their enterprise.

Many of the strategies examined in this study fit a "pro-enterprise" perspective whereby individual operators accept products from upstream in the supply chain and pass waste and costs downstream. This economic rationalist approach is primarily enterprise focused and short term rather than environmentally based and long term (Stern and Dietz 1994). To minimize a pro-enterprise stance and to enhance enterprise relationships with the environment requires an improved understanding of environmental responsiveness. Environmental responsiveness embodies knowledge, attitude, and strategic action (Figure 5).

One of the major impediments to responsible environmental responsiveness is a lack of knowledge about issues and a subsequent inability to develop and mobilize strategic action to manage the environment. Lack of knowledge may add to the perception of complexity associated with protecting the environment. That is, operators want to be environmentally responsive but do not have the know-how. Conversely, some operators may have the knowledge but not the expertise or the financial capacity to take sustainable environmental action. Other operators may be concerned that, as a single enterprise, their action will not make a difference to the environment so their potential investment will be dissipated. 


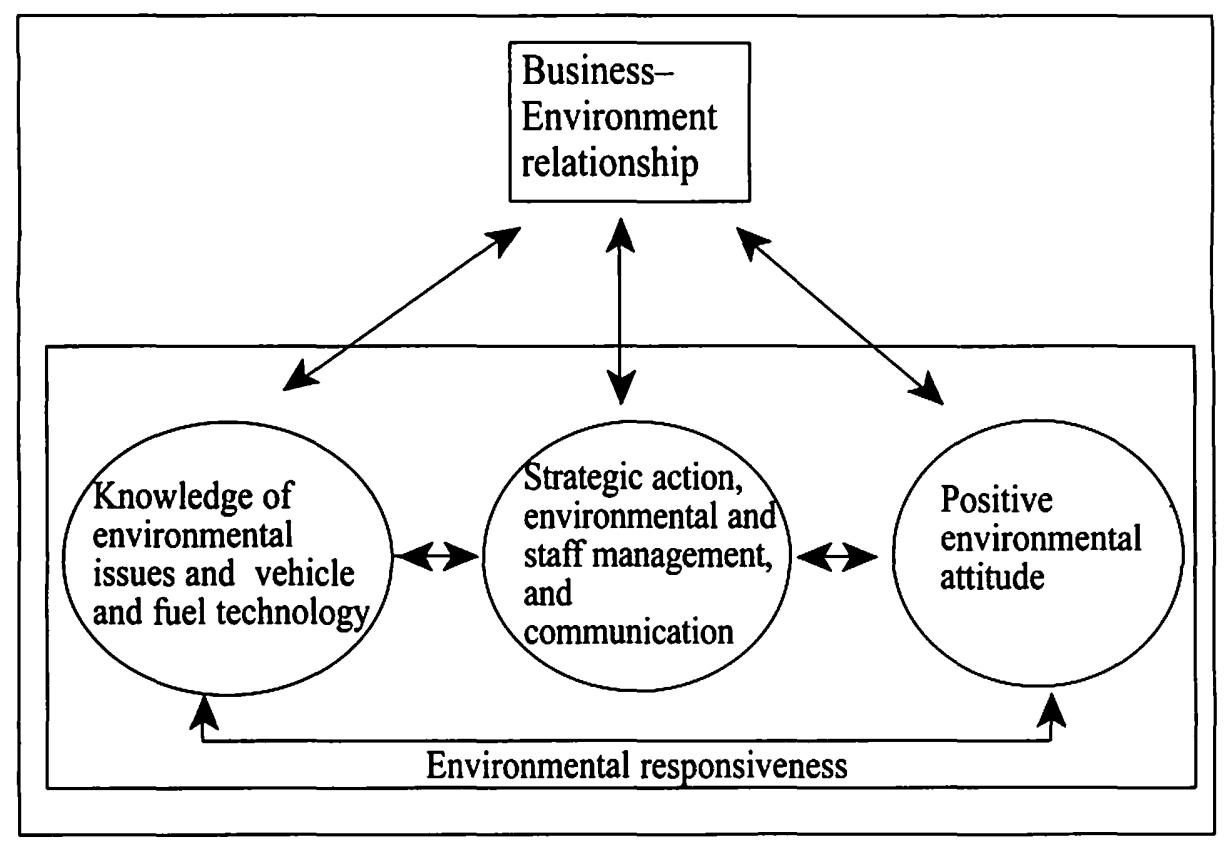

Figure 5. Factors contributing to environmental responsiveness

Schein's (1984 p. 3) frequently quoted definition of culture assists in understanding the basis of environmental responsiveness. Culture is the pattern of basic assumptions that a business has invented, discovered, or developed logically in learning to manage environmental issues. Culturally, environmental responsiveness diffuses throughout a business, affecting all people and facets of operation and business practice. As suggested in Figure 5, maintaining a business-environment relationship requires knowledge and a convergence of attitudes between pro-enterprise and pro-environment, as well as behavior that leads to environmental responsiveness (Rannikko 1996). Communication with and the training of staff to understand the "correct" way to perceive, think, and feel in relation to these problems is essential for an enterprise to become fully responsive to the needs of the environment.

Becoming environmentally responsive is a complex process for any enterprise. In addition to the enforcement of environmental regulations and subsequent monitoring of compliance, it involves engendering moral responsibility (Hines et al. 1987) or what might be termed "good citizenship," understanding 
the processes of social diffusion of industry knowledge (Manzo and Weinstein 1990), and as managing strategically. If environmental issues are officially recognized by management through integration in the business strategy, the likelihood of employees and customers being more receptive to environmental issues and activities increases. Unfortunately, operators do not know how to integrate environmental expenditure into their planning and budgets, nor is there a systematic process of environmental auditing in place. The need for businesses to engage in industrywide education and networking is of foremost importance in order for them to become environmentally responsive. Training and benchmarking are among the most effective routes to improve energy and waste management in the bus and coach industry.

All of these recommendations require a policy change for the bus and coach industry. Governments need to view operators in the bus and coach industry as conservative consumers. By focusing on the improvement of processes, it is necessary to identify the (often competing) interests of business and environmental objectives and seek realignment of a common objective. The policy change has to be an approach that seeks to change attitudes and business strategies by addressing the costs of not doing things by operators in relationship to the environment, and by identifying typical problems and preventive management programs.

\section{Acknowledgments}

The project reported in this article was conducted by the Institute of Transport Studies and sponsored by the Greenhouse Gas Studies Challenge Unit (GCU), Canberra, Australia.

The author wishes to thank Professor David Hensher for his comments on an earlier draft of this article and his contribution to the GCU study. The author also acknowledges Jenny King and Michelle Coulson for their contributions to the GCU study. Thanks are also due to two anonymous reviewers of this article for their valuable comments. 


\section{Endnote}

1. For a copy of the survey, contact Professor Brewer at the Institute of Transport Studies, C37, University of Sydney, NSW2006, Australia; phone: 6129351 0071; fax: 6129351 0088; email: itsinfo@itsusyd.edu.au.

\section{References}

ABCA. 1998. Australian bus and coach association membership list. Unpublished data.

Apelbaum Consulting Group. 1997. The Australian transport task, energy consumed and greenhouse gas emissions, Report prepared for the Department of Primary Industries and Energy, Volume B-Report, Canberra, September.

Bhate, S., and K. Lawler. 1997. Environmentally friendly products: Factors that influence their adoption. Technovation 17 (8): 457-465.

Brewer, A. M. 1994. The responsive employee: The road towards organisational citizenship in the workplace. Sydney: Allen and Unwin.

BTCE. 1996. Estimates of the urban transport task. Unpublished data, Canberra.

Bureau of Tourism Research. International visitor survey, Table 39.

Dickson-Simpson, J. 1998. How diesel can get clean away from gas. $B C A$ (NSW) Bulletin, April: 34-36.

Erdos, G. 1998. TransAdelaide. Personal communication.

Hines, J. M., H. R. Hungerford, and A. N. Tomera. 1987. Analysis and synthesis of research on responsible environmental behavior: A meta-analysis. Journal of Environmental Education 18: 1-8.

Manzo, L. C., and M. D. Weinstein. 1990. Behavioral commitment to environmental protection: A study of active and nonactive members of the Sierra Club. Environment and Behavior 19: 673-694.

Mills, E. 1998. The coming storm: Global warming and risk management. Risk Management 45 (5): 20-27.

Rannikko, P. 1996. Local environmental conflicts and the change in environmental consciousness. Acta Sociologica 39 (1): 57-72.

Schein, E. 1984. Organizational culture and leadership. San Francisco: Jossey Bass.

Stern, P. C., and T. Dietz. 1994. The value basis of environmental concern. Journal of Social Issues 50: 65-84. 
Taylor, J. 1998. Global warming: The anatomy of a debate. Vital Speeches of the Day 64 (11): 335-340.

\section{About the Author}

ANN M. BREWER is an associate professor of management at the Institute of Transport Studies, the University of Sydney. She is also the director of ITS Programs in Logistics and Supply Chain Management and Bus and Coach Management in New South Wales and Western Australia. 